\title{
La corrupción en la contratación estatal: ¿entre la etiqueta y la acción social?
}

\author{
Corruption in the public contract: between the label and the social action?
}

\author{
Carlos Fernando Amaya Rodríguez \\ Institución Universitaria Colegios de Colombia, Colombia \\ Laura Cristina Hernández \\ Abogada, Colombia \\ Zuleyma Méndez Prada \\ Abogada, Colombia
}

\begin{abstract}
RESUMEN La corrupción como un fenómeno propio de la contratación estatal es uno de los problemas sociales con mayor trascendencia en la sociedad actual. Cuando ocurre un caso de corrupción, el proceso de contratación ya no estará dirigido a la satisfacción del interés general, sino a los intereses personales de los agentes del proceso contractual, lo que afecta el bienestar de la comunidad. El anterior panorama permite evidenciar e identificar la presencia de una serie de categorías propias de la sociología jurídica por medio de los cuales se hace necesario hacer una revisión de la corrupción desde la óptica de esta disciplina.
\end{abstract}

PALABRAS CLAVE Interés general, contratación estatal, corrupción, acción social, etiqueta, control penal.

ABSTRACT Corruption as a separate phenomenon exists and per state procurement is one of the most significant social problems society that exists today. Corruption during the recruitment process will no longer be addressed to the satisfaction of general interest, but in the pursuit of personal interests of the agents of the contractual process thus affecting the welfare of the community. The above scenario makes evident the presence of a number of own categories of legal sociology through which necessitates a revision of corruption from the perspective of this discipline.

1. El presente artículo es resultado de la investigación realizada en el marco del proyecto «La corrupción en la contratación estatal desde una mirada sociojurídica», adscrito a la línea Derecho, Estado y Sociedad del grupo de investigaciones sociojurídicas UNICOC GISU. 
KEYWORDS General interests, state procurement, corruption, social action, label, criminal control.

La eliminación de la corrupción aumenta los recursos para proporcionar bienes públicos.

Ernesto Matallana Camacho

\section{Introducción}

La satisfacción del interés general es una de las principales tareas que debe buscar y garantizar un Estado social de derecho tal y como lo es Colombia. Así pues, el Estado tiene una serie de herramientas en instituciones a su servicio para cumplir con dicha finalidad. Una de ellas es la Contratación Estatal (como finalmente fue definida por la Ley 80 de 1993), en donde el Estado por medio de una serie de principios y reglas que orientan el proceso busca la satisfacción de dicho interés. El anterior proceso pretende brindar a la comunidad servicios públicos con calidad, continuidad y eficiencia.

De la mano de este instrumento de alto impacto y trascendencia para la sociedad, se gesta una de las "problemáticas» que más flagela tanto al Estado como a la sociedad en sí: la corrupción, evento en el cual los dineros del Estado no son destinados para la búsqueda, satisfacción y garantía del mencionado interés general o público, sino que, por el contrario, son utilizados por intereses de particulares, que por lo general hacen parte del proceso contractual del Estado.

La corrupción se entiende como una acción social y un fenómeno que se inyecta en todos los agentes del proceso contractual del Estado y en las demás formas de gestión de la función administrativa. Sin embargo, desde las teorías y posiciones de la sociología jurídica, la corrupción debe ser entendida como una etiqueta, pues es una definición y valoración dada por los agentes y observadores del proceso sobre determinadas acciones que se desarrollan en torno a éste.

En el presente texto se realizará, de manera preliminar, un encuadre teórico del concepto de etiqueta, con el propósito de entregar mayor densidad a esta categoría que luego converge con el fenómeno de la corrupción. Paso seguido, el texto abordará la distinción entre los conceptos de etiqueta y acción social como punto de partida para el análisis de la corrupción en la contratación estatal en Colombia desde la sociología jurídica y el encuadre de ésta dentro de la categoría conceptual correcta, pasando a una revisión de los diferentes discursos y definiciones que los agentes del proceso contractual administrativo dan sobre la misma. Posterior a ello se realizará una presentación de las principales acciones o prácticas que son etiquetables bajo el sello de corruptas por parte de los agentes del proceso. En armonía con lo anterior se procederá al abordaje de la normativa diseñada por el Estado para combatir la corrupción, realizando una revisión desde las etapas del ciclo del control penal e intentando concluir si estos 
instrumentos han sido la solución o los agravantes al problema que se desprende de las acciones sociales etiquetables como corruptas.

Finalmente, se realizará una exposición de las consecuencias y efectos de las acciones sociales etiquetadas de corruptas en la sociedad. El anterior propósito justificado con base a la vulneración que se da para con el interés general que encierra en la corrupción, situación que evidentemente genera un efecto dominó en otros ámbitos, que tanto de manera directa como indirecta se desprenden y dependen de ella.

\section{Preliminares, encuadre teórico del concepto de etiqueta en el ámbito sociojurídico}

Como punto de partida de este artículo resulta pertinente tener una claridad sobre el concepto principal sobre el que gira el trabajo y es precisamente el establecimiento de la corrupción como una etiqueta y no su conceptualización como acción social en propiedad.

Así pues, conviene mencionar que el profesor Germán Silva García, experto en sociología jurídica y criminología, dice que la etiqueta es un instrumento por medio del cual se da una valoración o definición de los agentes de poder sobre determinadas acciones, que por lo general apuntan al otorgamiento de un desvalor a la acción y resultan un punto de partida del proceso de criminalización y control social (Silva García, 2012: 234-235).

La etiqueta debe ser entendida no solamente como una simple categorización de una actividad, pues ella en sí encierra una estigmatización de un comportamiento social en específico, a efectos de darle una connotación negativa o desmejorada.

Ahora bien, resulta conveniente exponer que la etiqueta es resultado del proceso de etiquetamiento en donde se busca consolidar un determinado grupo de acciones como desviadas y objeto de reproche por parte del control penal y social, entendiendo al delito más como una reacción social que como una acción. María Dolores Sancho afirma:

El enfoque del etiquetamiento problematiza la reacción social, es decir, que la toma como variable y no como una constante ya que considera que un mismo acto genera reacción o no dependiendo de las víctimas, victimarios, contextos, etcétera. En otros términos, considera problemático lo que generalmente se da por supuesto: que ciertas conductas son intrínsecamente desviadas y son así definidas por los miembros de un grupo (Sancho, 2014: 68).

Por ello que la etiqueta sea impuesta sobre conductas ya desarrolladas y ejecutadas, que por lo general son generadas en un amplio margen de reincidencia, siendo así apreciables como una problemática social.

Ahora bien, el origen del proceso de etiquetamiento tiene sus orígenes en la década de los sesenta en Estados Unidos, exponiéndose como una corriente de la criminología enfocada a dar respuesta a los agentes sociales, y en específico a los Estados (como detentores del poder político), de las causas del delito y la criminalidad (Conf Lamnek, 1987: 35). 
Los representantes de esta teoría y escuela más conocidos son Edwin Lemert y Howard Becker, y a Lemert como un refundador de la teoría, quienes en esencia encontraron en las problemáticas sociales de la década de los sesenta del siglo XX la posibilidad de establecer patrones y criterios para el establecimiento de conductas reprochables y como consecuencia etiquetables como delictivas, generando en algunos casos el desvalor a las exigencias sociales, como la igualdad racial, los derechos de las mujeres, la exigencia del respeto por la autonomía de los países del Tercer Mundo y la finalización de los procesos colonizadores del siglo XIX.

En este orden de ideas, la etiqueta se presenta como el resultado del proceso de etiquetamiento, en donde se pone en jaque la idea de que las normas penales sancionan las conductas socialmente más reprochables, argumentando que, en realidad, esas normas responden a los intereses de grupos sociales poderosos, muchas veces sintetizados en líderes morales, con aptitud para decidir e influir en lo que legalmente está prohibido y lo que está permitido. Lo que acontece es, primeramente, un proceso de calificación, en un contexto de interacción en el que las personas le atribuyen a otro la condición desviada. Si una persona incumple estos mandatos normativos grupales, seguramente, será considerada desviada desde la visión de esos grupos. Sin embargo, a la inversa, «desde el punto de vista del individuo que es etiquetado como desviado, pueden ser outsiders aquellas personas que elaboraron las reglas, de cuya violación fue encontrado culpable» (Lemert, 1951: 57). Por lo tanto, el crimen y su conceptualización serán resultado del «proceso social de definición y selección de ciertas personas y conductas etiquetadas como criminales. Delito y reacción social son términos interdependientes e inseparables» (García, 1999: 776). Lo anterior en la medida que con el etiquetamiento se da una respuesta desde los agentes sociales a las interrogantes relativos a la causa de la delincuencia.

En resumen, la etiqueta es el resultado del proceso de etiquetamiento, en donde por medio de la valoración empírica de la realidad, es decir, la categorización que sobre las acciones realizan los agentes sociales, expresando valoraciones y juicios de reproche sobre las mismas en aras de generar un mayor control social y penal sobre éstos.

\section{¿La corrupción una acción o una etiqueta?}

Erróneamente, la corrupción ha sido definida como un fenómeno social. Sin embargo, el concepto de corrupción, en términos sociológicos, está enmarcado dentro de la categoría conceptual de etiqueta. Es ésta la que ha de recaer sobre las diferentes acciones sociales divergentes del deber ser de la norma que se desarrollan en los procesos contractuales del Estado.

Para comprender los conceptos de acción social y de etiqueta, resulta necesario definirlos. Lo anterior a fin de proseguir con la revisión de las diferentes definiciones y conceptos que se encierran en entorno a la etiqueta de corrupción.

En primer lugar, las acciones sociales en palabras del reconocido investigador German Silva García son compartimientos u actos humanos, pero que denotan impacto en 
la sociedad (Silva García, 2012: 97). Dicho impacto se manifiesta en razón al mensaje o sentido que la realización de la acción trasmite a los otros como acciones comunicativas (Silva García, 2012: 97), pues generan un impacto en el entorno social y trasmiten las emociones o los fines de su autor.

Ahora bien, la etiqueta se presenta como un instrumento para la definición por parte de los agentes sociales (que ostentan la potestad para emitirla) del sentido y valoración de determinadas acciones. Puede decirse entonces que son el resultado de un verdadero juicio de valor sobre el sentido que encarna la acción. Esta etiqueta se convierte entonces en un signo distintivo aplicable tanto a personas como a comportamientos con el que se busca dejar presente, por lo general, el desvalor otorgado y parte del proceso de criminalización. En lo anterior la etiqueta o estigma (como también se le conoce en el ámbito de la sociología jurídica) se presenta como una herramienta facilitadora de los procesos de control penal (Silva García, 2012: 234-235), pues se definen por parte de los agentes los alcances de las conductas que enmarca la etiqueta y que deben ser sancionados por el poder punitivo del Estado.

Frente al panorama planteado se hace necesario una revisión de la etimología de la palabra corrupción, con el fin de articular las categorías conceptuales previas con el desarrollo del presente apartado. Ésta proviene del latín curruptus, que indica descomposición, así como desintegración de algo. En el marco del proceso de la Administración Pública y de los procesos contractuales del Estado, implica la desintegración de los criterios, reglas y principios establecidos para el ejercicio de las mencionadas actividades, es decir, que los agentes contractuales desconocen las obligaciones que deben atender con el proceso anteponiendo sus intereses personales sobre el interés general y la satisfacción de la necesidades públicas, las cuales son el motor de los procesos contractuales del Estado.

Los agentes del proceso contractual del Estado han propendido a dar una definición conceptual sobre lo que a su criterio se entiendo por corrupción. La sociedad colombiana representada por sus ciudadanos de a pie coloquialmente han comprendido el fenómeno como un «mal necesario para la ejecución de la actividad de la Administración», que es «inevitable que roben pero que al menos hagan algo», «servidor público que no robe no está haciendo bien su trabajo», entre muchas otras afirmaciones que evidencian el sentir de la sociedad frente a la corrupción, lo que da cuenta del proceso de etiquetamiento descrito en el apartado anterior en la medida que se hacen juicios de reproche y valor sobre los acciones sociales, categorizándolas como negativas y desviadas.

De lo anterior es importante mencionar que esas afirmaciones denotan que la corrupción es sinónimo de impunidad e ineficacia de las instituciones del Estado. Así las cosas:

la sensación de impunidad lleva a confirmar la irrelevancia del respeto por la ley, tanto por parte de aquellos que la transgreden normalmente como por parte de aquellos que normalmente observan la ley, pero pueden enfrentarse a situaciones específicas de 
posible apartamiento de las normas. La impunidad se extiende no solamente a delitos contra la administración cometidos por funcionarios públicos, sino que además comprende otros delitos - en especial los delitos de cuello blanco- que gozan del mismo grado de impunidad en muchos de los países de la región (Lausana y Toro, 2009: 46).

De lo anterior se desprende un serio problema en torno al grado de aceptación o resignación de la sociedad ante la corrupción y los serios cuestionamientos sobre la eficacia de las instituciones públicas frente a la problemática en torno a estas prácticas.

En el ámbito de la doctrina, la definición de la corrupción tiene multiplicidad de enunciados. Jesús Bejarano afirmó que «hay corrupción cuando una persona ilícitamente pone sus intereses personales por encima de los intereses generales que está obligado a servir» (Bejarano Ávila, 1996: 84). Puede entenderse entonces que la corrupción es aquel evento en donde alguno de los partícipes dentro de los procesos contractuales del Estado, de manera ilícita e injustificada, antepone sus intereses particulares sobre el interés general, que es el principio rector y fundamental del Estado social de derecho.

De igual forma es importante advertir, en lo que refiere al concepto de corrupción, que ésta es ejercida por los individuos que divergen del deber ser la contratación (búsqueda y medio para la satisfacción del interés general) por lo cual:

la noción de corrupción está anclada en casi todos los autores en la violación del deber ser de probidad del funcionario (que debería actuar sine et studio, diría Max Weber) y en su enriquecimiento personal. En suma, la corrupción es una desviación de la conducta de un funcionario público, que se aparta de las normas establecidas para ponerse al servicio de intereses privados [...] Existe corrupción cuando una persona, ilícitamente, pone sus intereses personales por sobre los de las personas y los ideales que está comprometido a servir (Pegorano, 1998: 4-5).

De lo anterior puede concluirse de manera categórica que la corrupción es la separación de todos los agentes del proceso de los principios establecidos por el legislador para una correcta contratación pública.

Transparencia por Colombia es una ONG que se ha dedicado al estudio de las problemáticas que se construyen en torno a la corrupción en el país, definiendo en su valoración lo que se debe entender por corrupción. Dicha definición está dada en el marco que la corrupción es un:

abuso de posiciones de poder o de confianza, para beneficio particular en detrimento del interés colectivo, realizado a través de ofrecer o solicitar, entregar o recibir, bienes en dinero o en especie, en servicios o beneficios, a cambio de acciones, decisiones u omisiones (Unger)

Puede evidenciarse que por corrupción se entiende la anteposición de los intereses particulares sobre el interés general.

El anterior panorama fue el sustento para la construcción del proyecto que enmarca la Agencia Colombia Compra Eficiente, así como la configuración de la visión de la mencionada agencia del Estado: 
La visión de Colombia Compra Eficiente es ser la organización del Gobierno Nacional que lidera y coordina el Sistema de Compra Pública de Colombia, asegurando el óptimo valor por dinero con transparencia en la compra y contratación pública en Colombia y generando confianza a todos los partícipes del sistema (Agencia Colombia Compra Eficiente, disponible en http://www.colombiacompra.gov.co/es/vision).

Tomando como visión entre líneas el diseño e implementación de estrategias que eliminen las practicas identificadas y catalogadas como corrupción.

La Agencia Colombia Compra Eficiente, ${ }^{2}$ en su condición de órgano rector de la contratación administrativa del Estado Colombiano, ha expuesto que la corrupción es una de las problemáticas que mayor impacto tiene sobre los procesos de gestión contractual del Estado, situación que afecta la competitividad del Estado frente a las contrataciones privadas, generando retraso en la infraestructura y la prestación deficiente de los servicios públicos.

La directora de la mencionada agencia estatal precisa que el cumplimiento de lleno de los requisitos relativos a la publicidad y transparencia consagrados en la norma permite no sólo la transparencia de los procesos, sino la competitividad de los mismos:

La contratación pública es la forma de materializar la política pública. El Gobierno Nacional, los departamentos, los municipios y todas las entidades estatales cumplen su misión a través del sistema de compra pública. Los cambios en el sistema buscan hacer más fácil y simple la contratación pública cumpliendo con el objetivo de optimizar los recursos públicos, dinamizar la industria de bienes y servicios y mejorar la transparencia del sistema (Revista Semana, 2014). ${ }^{3}$

Se evidencian dos aspectos importantes del mensaje de la citada directora. El primero, que la finalidad de la contratación pública es ser medio para el cumplimiento de los fines del Estado por medio de la gestión indirecta ${ }^{4} \mathrm{y}$, en un segundo momento, que el sistema necesita una reconfiguración que mitigue la corrupción y la haga eficiente y competitiva.

Es importante anotar que los efectos de la corrupción recaen sobre diversos aspectos de la gestión del Estado. Un ejemplo de ello es la ineficacia de la actividad estatal representada en la violación de derechos humanos, desigualdades económicas, aumento del índice de la pobreza, entre otros. La anterior situación la pone de manifiesto la directora de la Corporación Transparencia por Colombia, Elisabeth Ungar Bleier,

2. La Agencia Nacional Colombia Compra Eficiente ha sido creada en el año 2012 con la finalidad de actualizar y optimizar los procesos contractuales de la Administración y, sin lugar a dudas, como una estrategia de la lucha contra las prácticas catalogables como corrupción.

3. «El impacto de las compras estatales», entrevista con María Margarita Zulueta, directora de la Agencia Nacional Colombia Compra Eficiente, Semana, 27 de septiembre de 2014, disponible en http://bit. ly/2vQ7fzy.

4. Por gestión indirecta se debe entender aquélla que desarrolla el Estado, apoyado en terceros colaboradores (por lo general son particulares), para cumplir sus fines. 
quien afirma (Lausana y Toro, 2009: 46) que el grado de corrupción es sinónimo de los niveles de atraso económico y violación de derechos humanos.

Es claro que la corrupción es una de las problemáticas que más ha trascendido dentro de la evolución de la sociedad y la conformación del Estado moderno, afectando diversos ámbitos del Estado, así como a sus ciudadanos, concibiéndose entonces como «un flagelo que está presente en todos los países, afectando la estabilidad de sus sistemas políticos y de sus instituciones, lesionando sus economías y la moral de sus sociedades» (Martínez, Enrique y Ramírez, 2006: 149).

Se confirma una vez más el significado de corrupción, el cual puede entenderse como una serie de hechos que atañen a todos los agentes que conviven en la sociedad, siendo el más afectado la misma Administración Pública. Pues con la definición dada en líneas anteriores, la corrupción se resume a la sobreposición de los intereses particulares sobre el interés general, situación que hace inocua una de las principales finalidades del deber ser del Estado, que no es otra que la satisfacción de citado interés.

Lo anterior resulta, en suma, en la conceptualización y categorización de la etiqueta, es decir, del reproche y desvalor sobre determinadas acciones que en el marco de la contratación estatal están llamadas a ser sancionadas y constreñidas por parte del control social y penal. Siendo así, entonces, la materialización conceptual de la etiqueta de corrupto y corrupción permitirá adelantar el proceso de estigmatización y etiquetamiento de una amplia pluralidad de actuaciones en el marco de la contratación estatal o administrativa.

En coherencia con lo hasta ahora expuesto, el problema que encierra per se el término de corrupción es uno de los males que han con mayor fuerza aquejado la actividad del Estado y por consecuencia a la sociedad en general, situación que no es ajena a la precepción de la ciudadanía, evidenciándose como un flagelo en el mundo. En efecto, en el año 2013, la ONG Trasparencia Internacional desarrollo una evaluación sobre el Índice de Percepción de Corrupción: se evaluaron 177 naciones en todo el mundo. El panorama del continente americano refleja una radiografía de la realidad de los problemas de corrupción inherente a los Estados del continente.

El informe mencionado «califica de o a 100 la percepción sobre corrupción en el país y en ese estudio Colombia tiene 36 puntos, muy por debajo del promedio regional que es de 45 puntos. En la región estamos en el lugar 18» (El Tiempo, 2013). ${ }^{5}$ Dentro de los varios criterios tomados por la evaluación, uno de ellos es el accionar del Estado para frenar el fenómeno de la corrupción, cuyos resultados evidencian una estrecha y continua relación entre la corrupción y el Estado, presente en la historia de la sociedad de manera continua.

Es, entonces, prudente explicar que la corrupción no es más que una etiqueta (como se mencionó al principio del presente texto) que ha de recaer y encerrar a una serie de acciones o prácticas que en conclusión vendrían a ser en sí el trasfondo de la corrup-

5. «Corrupción en Colombia sigue siendo alarmante: Trasparencia», El Tiempo, 2 de diciembre de 2013, disponible en http://bit.ly/2veiW6k. 
ción. Es la construcción y elaboración de la etiqueta lo que preocupa a los doctrinantes, políticos, operadores administrativos, quienes han definido este comportamiento como algo negativo y de nefasto impacto para la sociedad y la institucionalidad del Estado. Así, pues, de la revisión de las definiciones trabajadas a lo largo de este apartado se advierte que la corrupción no es en sí una acción social, sino una etiqueta que ha de recaer en las acciones que encuadren en la definición categórica que se encierra en la etiqueta.

Por lo que no es prudente hablar del fenómeno social de la corrupción como una acción social, sino por el contrario lo correcto es hablar de prácticas, actividades y actitudes que son contrarias al deber ser normativo y que trasmiten un mensaje de ilegalidad. Por tal motivo son entonces etiquetadas bajo el sello de corruptas.

Es claro entonces que la corrupción, si bien trasmite un mensaje, su estructura no encaja en las dimensiones de acción social, sino de etiqueta. Lo anterior nos permite concluir que lo correcto, entonces, al menos en el plano sociojurídico es hablar de prácticas sociales que son etiquetables bajo la categoría conceptual de corrupción. Dicha etiqueta y su valoración ya han sido definidas y conceptualizadas por medio de los diferentes agentes del proceso contractual del Estado.

\section{Las prácticas o acciones que son etiquetables bajo la categoría de corrupción}

Como se mencionó en el apartado anterior, la corrupción no es más que una etiqueta que encierra una serie de acciones o prácticas que son resultado de un análisis de la realidad del proceso de contratación administrativo de los Estados. Por ello sería posible afirmar que no existe corrupción en sentido estricto, sino por el contrario, existen acciones o prácticas etiquetables como corruptas.

Estas acciones o prácticas son hechos que trascienden y trasmiten un mensaje a la sociedad en la que se generan; por lo que para efectos sociológicos han de ser entendidas como acciones sociales de conformidad con la definición que sobre dicha categoría han dado autores como Germán Silva García.

La trascendencia o el mensaje que se encierra en torno a ellas no es otro que el de anteponer los intereses particulares sobre el interés general, por lo que se ha de concluir del mensaje que la contratación estatal o administrativa no es un medio de gestión indirecta de la función administrativa y del interés general, sino por el contrario un medio para la gestión de intereses personales tanto del proponente/futuro contratista, así como del funcionario o servidor público.

El presente apartado pretenderá hacer una descripción de dichas prácticas, en especial el soborno, y la construcción de los pliegos sastre o a la medida, que son en principio los medios excelsos para desconocer el principio de la selección objetiva del contratista y el cumplimiento de los fines de la contratación.

Las acciones sociales que son sujetas a ser etiquetadas de corruptas son el resultado de la rigidez del sistema, su carácter ritualista, las leyes del mercado de oferta y demanda presentes en la contratación estatal, siendo claro entonces que el mismo sistema se presenta en principio como la causa del problema. Profundizando en lo anterior, la 
misma sociedad y los agentes del proceso contractual dentro de diferentes variables, han decidido aceptar a la corrupción como un resultado de un Estado que no es más que una Institución incapaz de autocontralarse o autorregularse. De igual manera no se debe exclusivamente la responsabilidad al agente o funcionario del Estado, porque para que este tipo de acciones se desarrollen se necesita de dos, siendo el segundo de ellos el contratista o proponente, completando así la ecuación de oferta y demanda. Es bajo el anterior escenario en el que la figura del soborno se presenta como la herramienta predilecta para ser ofertada o demandada según la posición que se fije en las relaciones contractuales de la Administración Pública.

Pues bien, el soborno puede decirse que es una de las acciones que mayor tráfico tiene en el mundo de la contratación estatal. Que en esencia no es más que el ofrecimiento, petición, y recepción de dadivas (que pueden ser de distinta índole) a cambio de un beneficio o concesión especial dentro del proceso contractual.

Definición que no es ajena a la realidad, pues:

los individuos están dispuestos a ofrecer sobornos a los funcionarios para eludir las normas y, triste es relacionarse, los funcionarios tienen de vez en cuando la tentación de aceptar estos sobornos. La identificación de estas fuentes relacionadas con las políticas de la corrupción es obviamente útil en traer bajo control (Mauro, 1997: 8).

Es importante hacer presente que la anterior apreciación y análisis del contexto social del profesor Paolo Mauro, es encuadrable no solo dentro de la contratación estatal, sino adicionalmente es una acción social que está presente en muchos eventos de la cotidianeidad social.

El soborno, permite entonces direccionar el proceso de selección del contratista, pues con las transacciones de prebendadas entre proponente y funcionarios se podrá en la medida de los escenarios posibles, generar la adjudicación del contrato a dedo lo que en palabras más tecinas implica desvirtuar el proceso de selección objetiva.

Esta práctica tiene diferentes modalidades de materializarse en el mundo de la contratación estatal, desde la preparación de los estudios y diseños previos hasta el momento de la adjudicación misma del contrato, generando varios impactos negativos sobre el proceso en sí. El primero de ellos es sin duda la adjudicación del contrato sin cumplir con el lleno de los factores determinados para la evaluación o incluso los requisitos habilitantes, vulnerando de plano los principios de favorabilidad de oferta (que debe regir el proceso de selección de los contratistas del Estado), y el principio de la selección objetiva. Todo lo anterior podría implicar que el contrato no logré satisfacer las necesidades y el interés general para el que fue estructurado.

De otro lado, el soborno implica una serie de sobrecostos o gastos adicionales, que han de impactar sobre la ecuación y el equilibrio económico del contrato estatal. Esto debido a que los sujetos que realizan esta actividad imputan la carga económica de la prestación (que implica en sí el soborno) a los recursos que ha de ejecutar el contrato estatal. Lo anterior es visible, por ejemplo, en el cobro de comisiones del valor total del 
contrato por parte del adjudicante al adjudicatario o viceversa, lo que se conoce como la comisión o coloquialmente como la tajada.

Es claro entonces que el soborno tiene una clara incidencia en lo económico y los fines que persigue el contrato estatal, sin embargo, vale la pena mencionar que para algunos esta acción puede llegar a tener una connotación positiva, bajo el entendido de que el soborno puede agilizar el proceso burocrático y económico que se desarrolla con ocasión de un contrato estatal, pues cuando:

los funcionarios reciben sobornos por su gestión, tienden a ser más diligentes, los empresarios evitan las regulaciones engorrosas, agilizando el proceso de inversión que estos requieren. Esas acciones, desde el punto de vista de la eficiencia y no de la redistribución de los recursos, pueden tener efectos benéficos en lo económico (Ruiz, 2013: 15).

Se debe ser categórico en que la visión positiva que sobre el soborno pudiere existir se basa meramente, y como afirma el autor del texto citado, en criterios y términos de eficiencia, pues es claro que la relación contractual que pudiera surgir, así como todos los subproductos de esta actividad, estarán fundados en uno de los principios generales del derecho, como lo es la buena fe, así como en el principio de la moralidad administrativa, lo cual convierten al soborno en abiertamente contrario al deber ser de la norma, por ende, antijurídico.

No sobra decir que son más los contras que los pros que representa la práctica del soborno para la contratación estatal. Ejemplo de ello son los atrasos en infraestructura y la falta de atención de las necesidades sociales, la demora en los procesos administrativos y la gestión pública (pues lo servidores de lo público siempre estarán a la espera del ingreso adicional que para ellos representa el soborno), los sobrecostos que representa la acción aquí estudiada, que no sólo es asumida por el proceso contractual, sino que además es considerada por algunos autores como un impuesto a la sombra (Villamayor, 2001) el cual es abiertamente ilegítimo guardando amplia relación con las definiciones conceptuales que sobre corrupción se estudiaron previamente.

Es tan evidente la problemática que representa esta acción social, que sobre ella ha devenido el control penal (Silva García, 2012: 138), ${ }^{6}$ a fin de mantener e imponer el orden y statu quo que sobre la Administración Pública debe existir, siendo éste la prestación de servicios públicos, con calidad, continuidad y eficiencia, con la única finalidad de satisfacer el interés general y las necesidades colectivas.

Por ello, desde la institución del poder punitivo del Estado se ha tipificado como conducta punible al soborno bajo el nombre de cohecho, definiendo como verbos rectores de la actividad el dar o recibir dádivas entre particulares para con los servidores públicos (o viceversa) a fin de obtener beneficios en lo que al servicio y gestión de lo público se refiere.

6. En esta obra, el autor explica los orígenes del control social, el cual define como el conjunto de instituciones, disposiciones y prácticas destinadas a preservar o imponer un determinando orden para regular las relaciones sociales, concluyendo que el control penal es una especie del ya expuesto control social. 
La Corte Suprema de Justicia de Colombia, en su sala de casación penal, se ha ocupado de completar por vía jurisprudencial la tipificación de esta acción social, evidenciando el impacto que se desprende de esta conducta y afirmando que el soborno o cohecho:

Es germen activo de descomposición social y se considera como ruina moral de las naciones [...] El cohecho constituye una evidente corrupción. Por eso se le conoce con ese nombre, como también con el de baratería. Este último porque el funcionario se engaña a sí mismo al dar algo inestimable (la función pública) por cosa de menor valor (el dinero, la promesa remuneratoria) (Sentencia de la Corte Suprema de Justicia, 1976).

Queda de manifiesto entonces que la Corte evidencia que el comportamiento social del cohecho o el soborno presenta un mensaje y efectos claros, así como concretos. Es claro que el soborno se encuadernable dentro de la categoría de acción social, lo que a su vez permite hacer un proceso de etiquetamiento formal del comportamiento bajo el libelo de la etiqueta de corrupción.

Otra de las prácticas o acciones que se desarrollan en el marco de la contratación estatal es la colusión de proponentes. Esta práctica evidencia una contravención del ordenamiento jurídico, pues los proponentes generan alianzas, acuerdos, pactos, etcétera, entre ellos, a fin de hacerse adjudicatarios de los recursos que componen el contrato, violentando de esta manera el principio de la selección objetiva y pluralidad de oferta.

Una salvedad importante sobre esta práctica radica en que, en la mayoría de los casos de colusión, ésta es sólo desarrollada por los proponentes con una participación mínima, por no decir que nula de los funcionarios públicos inmersos en el proceso pre y contractual del Estado.

Ejemplo de lo anterior es la intervención en el periódico Ámbito Jurídico del abogado Gabriel Ibarra Pardo sobre la presentación de la Guía para combatir colusiones en las licitaciones. En dicha referencia el togado define que la presencia de la colusión en los procesos contractuales está dada cuando:

los oferentes conforman alianzas para distorsionar el proceso licitatorio, lo que implica que la adjudicación no es el resultado de propuestas basadas en el libre juego de la oferta y demanda, sino, por el contrario, la consecuencia de acuerdos ilegales que repercuten directamente en el patrimonio del Estado (Ibarra Pardo, 2011).

Así las cosas, se evidencian que las consecuencias de esta práctica son de contenido social, toda vez que afectar el patrimonio público es afectar a la sociedad en general.

Expresa el abogado Ibarra que la colusión de proponentes se puede presentar en diferentes etapas del proceso precontractual e incluso durante la ejecución del contrato (estando éste ya adjudicado). Las etapas identificadas con un alto grado de potencialidad de colusión son: i) la elaboración de los pliegos; ii) durante la presentación de las ofertas; y iii) durante la celebración del contrato. De las anteriores etapas se debe mencionar que en ellas también están presentes otras prácticas que pueden ser etiquetables de corruptas y que más adelante serán analizadas (Ibarra Pardo, 2011). 
Siguiendo con el ejercicio desarrollado para con el soborno, es claro que esta práctica también ha sido etiquetada como corrupta, así como también sujeta de un control penal.

Si bien, la conducta que implica la colusión o alianza de proponentes no está tipificada taxativamente dentro de la norma punitiva del Estado, sí es posible desarrollar un ejercicio desde la perspectiva del derecho administrativo buscando un símil con el tipo penal del concierto para delinquir. De este planteamiento no se puede perder de vista que la colusión significa una alianza entre diferentes proponentes los cuales configuran diferentes ofertas con el fin de capturar el Estado y su presupuesto.

Este acuerdo de voluntades e intereses de diferentes proponentes se hace análogo a la descripción normativa del tipo penal del concierto para delinquir. El código penal colombiano (Ley 599 de 2000) dispone en su artículo 340: "Concierto para delinquir. Cuando varias personas se concierten con el fin de cometer delitos, cada una de ellas será penada, por esa sola conducta, con prisión de tres a seis años».

La comisión del delito está en la obtención de la adjudicación de un contrato estatal, en abierta contravención de los principios de la selección objetiva, así como de la favorabilidad de oferta, situación en la cual se configuraría el injusto penal. Este concierto o colusión tiene gran arraigo en los procesos de selección de contratistas adelantados bajo la modalidad de subasta inversa por medios electrónicos. Lo anterior debido al poco control que puede ejercer la entidad en los momentos de las pujas o lances de los proponentes, que en muchos casos se encuentran por fuera de las instalaciones de la entidad.

Como se mencionó previamente, la construcción del pliego de condiciones es otro foco de prácticas etiquetables bajo la categoría de corrupción, pues con la injerencia de sobornos, alianzas entre proponentes y funcionarios públicos, la formulación del pliego de condiciones no será resultado de una fiel guía de los estudios y diseños previos de la etapa precontractual, sino del abierto direccionamiento del proceso por medio de la modalidad del pliego sastre o a la medida. Esta acción, en términos generales, consiste en diseñar bajo los intereses de las partes en común y a la medida de uno de los proponentes, desvirtuando la esencia de este instrumento para la selección objetiva del contratista y que permite establecer las condiciones de favorabilidad de las ofertas (favorabilidad entendida como aquella oferta que cumple con los requisitos establecidos para satisfacer el interés general y necesidades que han de ser atendidos con ocasión del contrato estatal), convirtiéndole en un instrumento para obtener fines e intereses de índole personal, ignorando abiertamente con esta acción el principio de selección objetiva que siempre deberá guiar el proceso para escoger un contratista cuya oferta satisfaga las necesidades de la Administración.

La elaboración de pliegos sastres evidentemente contraviene los principios contractuales de la transparencia e igualdad de proponentes y, como se mencionó al inicio de esta disertación, ha de tener por lo general estrecha relación con la práctica del soborno o cohecho.

Esta actividad genera desencanto por parte de los miembros de los diferentes gremios profesionales que interactúan en el campo de la contratación pública en el país, 
quienes afirman que la práctica de la elaboración del pliego de condiciones a la medida de ciertos proponentes, además de direccionar el proceso de selección, se presenta como un medio para la exclusión de pequeños proponentes en el marco del proceso precontractual.

Un ejemplo concreto del direccionamiento de procesos de selección del contratista por la realización de estas prácticas se aprecia en la denuncia realizada por el señor Carlos Alfredo Crosthwaite, presidente del Polo Democrático en Risaralda, sobre hechos ocurridos en el municipio de Santa Rosa de Cabal frente al presunto direccionamiento del proceso de licitación que buscaba la pavimentación de la carrera 23 en el sector La Hermosa. Afirma el denunciante que el proceso de selección lo relativo a:

los requisitos habilitantes contenidos en sus numerales: b) experiencia general y especifica; c) capacidad financiera, y d) capacidad organizacional, no promueven una sana y amplia competencia de más proponentes ni el crecimiento de la industria de la ingeniería, porque tal como están determinados son una forma de restringir la participación en este proceso de varios proponentes.?

Concluye el denunciante que el direccionamiento quedo probado, pues solo se presentó un único proponente, concluyendo que en el citado municipio no existen las garantías y respeto por los principios de la contratación estatal.

Esta práctica ha sido estudiada bajo la óptica del control social penal por medio de la tipificación de conductas en la legislación penal. Ejemplo de lo anterior es la tipificación del interés en la celebración indebida de contratos, actividad que esta debidamente tipificada según el artículo 409 del Código Penal Colombiano (Ley 599 de 2000). De igual forma en el ámbito del derecho disciplinario ha sido catalogada como una conducta considerada como falta gravísima.

Los precios artificialmente bajos es otra práctica que ha de ser catalogada como corrupta, pues consiste en ofrecer a la entidad una propuesta en la que con el menor precio se está satisfaciendo el objeto del contrato cuando la oferta es económicamente imposible cumplir. Esta situación genera que a futuro se alegue desequilibrio económico contractual, así como incumplimientos en virtud de los sobrecostos que se llegan a presentar.

Pareciere pues que son infinitas (sin temor a errar se puede decir que todas las acciones descritas previamente son solamente la punta del iceberg) las formas en las que pueden los servidores públicos, así como los proponentes, realizar acciones del alto contenido social etiquetables bajo el eslogan de corrupción e incluso es más desalentador que el mismo Estado no haya sido capaz de proponer una respuesta efectiva ante el problema. Podemos concluir que corrupción es una etiqueta (definida por diferentes agentes del medio) que recae sobre acciones de trascendencia social por el mensaje que transmiten, en donde se puede hablar claramente de una trasgresión al deber ser de la norma, pues, como se analizó en los ejemplos anteriores de acciones o prácticas, todas

7. «Denuncian 'pliegos sastre' en Santa Rosa de Cabal», La Tarde, 3 de septiembre de 2014. 
divergen de lo que la Constitución y la Ley exigen que debiera ser el adecuado proceso pre y contractual del Estado colombiano. Esta situación genera entonces un control penal sobre las mismas, mediante sanciones de tipo penal y administrativo contenidas en sendas compilaciones normativas (sobre esta situación trabajaremos en un apartado posterior) que a priori evidencian poca eficacia en virtud de la percepción ciudadana y los estudios adelantados en la materia, como los de la ONG Transparencia por Colombia.

\section{La normatividad en torno a la contratación estatal: ¿respuesta o un agravante del problema?}

La problemática social que gira entorno a las acciones sociales catalogadas o etiquetadas como corrupción en la contratación estatal no ha sido una situación indiferente para el Estado. Es correcto afirmar que tantos han sido los casos de corrupción en la contratación estatal como los intentos del Estado por generar respuestas, medidas, herramientas con el firme propósito si bien no de erradicarlas de plano, sí limitarlas a su mínima expresión.

En las dos últimas décadas, el Estado colombiano ha hecho un esfuerzo al menos en el plano normativo por combatir el fenómeno de la corrupción por medio de legislación y producción de la potestad reglamentaria, generando así un considerable número de normas que subyacen a los procesos de contratación estatal con la única finalidad de impedir que el proceso se desvíe de su pilar central.

La producción de estas normas son el resultado de la necesidad de que la ley o el reglamento indique la penalización de los actos etiquetables de corrupción, así como la definición de la etiqueta. Lo anterior con el fin controlar esta situación, no siendo Colombia un Estado ajeno a la producción de normatividad encaminada a enfrentar y controlar las acciones corruptas de las personas o entes sujetos de derechos.

Lo anterior es un claro ejemplo del ciclo que gira en torno al control social penal el cual se desarrolla en varias etapas y fases:

Las etapas son dos: 1) creación de las herramientas del control; 2) aplicación de los instrumentos de control. En cuanto a la primera aparece concentrada en los diseños de las políticas penales que deben ser implementadas, la cual obtiene su traducción en la planeación y creación de aparatos, normas, medidas y procedimientos que serían idóneos para cumplir con los cometidos perseguidos. Respecto a la segunda etapa, ella se expresa en tres fases: 1) vigilancia, 2) juzgamiento, 3) punitiva. La etapa de vigilancia tiene como agente central a la policía, con tareas de prevención y represión; la etapa de vigilancia encuentra como actores principales a los funcionarios que administran justicia, quienes deben interpretar el derecho y decidir sobre su aplicación definitiva (que en el caso del sistema jurídico del common law participan también en la creación del derecho); la etapa punitiva haya en el personal con competencias penitenciarias a sus agentes más relevantes, a cargo de la ejecución de las sanciones (Silva García, 2012: 141). 
El anterior planteamiento encaja perfectamente en el presente apartado, pues la primera etapa es la construcción de las herramientas con las cuales se va a desarrollar el control penal de las acciones etiquetables como corruptas. Es en este entendido en el que se fundamenta la tarea del Poder Legislativo y Poder Ejecutivo del Estado, instituciones que por medio del análisis de la realidad social proceden a identificar esta problemática y las posibles causas y consecuencias de las mismas a fin de diseñar una herramienta que permita poner freno al fenómeno.

Para comprender mejor el ejercicio desarrollado en la primera etapa, es necesario evidenciar el desarrollo normativo que el Estado colombiano ha construido en torno a la corrupción en la contratación estatal.

Teniendo en cuenta lo anterior, el marco normativo general específico de la lucha contra la corrupción se inicia de manera tajante en los noventa, cuando es expedida la Ley 190 de 1995, mediante la cual se dictaron normas laborales, administrativas, penales y financieras para erradicar la corrupción administrativa, pero que perdió vigencia y aplicabilidad efectiva al tener una gran variedad de modificaciones e igualmente luego de la expedición de la Ley 1.474 de 2011 (actual Estatuto Anticorrupción). Surge una duda en lo referente a por qué el grueso del desarrollo de las herramientas se produjo en los años noventa, en donde el diseño de estrategias para hacer frente a la corrupción dentro de los procesos contractuales, se construyó dentro de una innumerable lista de formalismos y tecnicismos que se estipulaban en procura del buen manejo de los recursos públicos. Ejemplo de ello son las metodologías de la urna tricable ${ }^{8}$ para el depósito de las ofertas, la construcción de un régimen de inhabilidades e incompatibilidades tanto para los proponentes como para los funcionarios públicos (este tema se fortaleció en la Ley 1474), entre otras situaciones que a priori están enfocadas a garantizar la satisfacción del interés general en la contratación estatal.

Con la Ley 8o de 1993 (Estatuto General de la Contratación Administrativa Pública), enmarcada en un nuevo modelo de Estado liberal, la normativa debe ajustarse a los requerimientos de transparencia que las políticas públicas y el cambio de forma de gobierno requieren, lo cual incluye, por tanto, la forma procedimental de contratación, habida cuenta que, si el fondo de la materia cambia, también lo deben hacer los procedimientos.

Es así como la Ley 80 de 1993, regida por principios, consagra en su articulado disposiciones atingentes a la transparencia, economía, responsabilidad, selección objetiva, buena fe, eficiencia y la eficacia del manejo de los recursos públicos, dentro de un marco legal encaminado hacia la facilitación de la misma mediante la aplicación de normas del derecho civil y comercial, para evitar mediante la aplicación de principios y procedimientos simples cualquier estado de corrupción.

8. Una urna tricable hace referencia a un contendor en donde eran depositadas las ofertas dentro de la etapa de convocatoria y recepción de ofertas en los procesos de licitación pública en Colombia, la cual estaba sellada y asegurada por tres cerraduras cuyas llaves no podían encontrarse hasta la fecha de cierre y apertura de la urna marcada en el cronograma del procedimiento, so pena que se declarare la nulidad del mismo. 
Con todo lo anterior, en el año 2007 se expidió la Ley 1.150, en la cual se devuelve el Estado a las rigurosidades y formalismos propios del Decreto Ley 222 del 1983, estableciéndose procedimientos estrictos y modalidades de contratación que hicieron retroceder en los pasos alcanzados con la Ley 80, y generar más dudas, interpretaciones y malos hábitos de transparencia en las entidades públicas.

Posterior a la expedición de la Ley 80, durante su ejecución y aunada a la expedición de la Ley 1.150 de 2007, se inició un proceso de reglamentación de la misma que ha llenado de decretos suspendidos y derogaciones al ordenamiento jurídico, impidiendo así una aplicación concreta de los principios establecidos por la misma y generando focos de corrupción por la variabilidad y la inestabilidad del régimen contractual del Estado, situación que configura sin oposición alguna el fenómeno de la inseguridad jurídica.

En el escándalo del grupo Nule en la ejecución de uno de los proyectos públicos más grandes de Bogotá, denominado el Carrusel de la Contratación, se defraudó al tesoro público en una cifra cercana a los ciento cincuenta millones de dorales americanos, generando una fuerte respuesta de rechazo social a lo ocurrido y una contundente crítica y presión por parte de los medios de comunicación. Esto llevo al inicio de lo que se considera la segunda etapa del control social penal, dando como resultados investigaciones, acusaciones y procesos penales y disciplinarios destacando la suspensión por tres meses del entonces alcalde mayor de Bogotá, Samuel Moreno, por parte de la Procuraduría (siendo hasta ahora el único que ha recibido un apremio por lo ocurrido).

En virtud del caso del Carrusel de la Contratación, el ciclo que representa el control social penal se reinició en la etapa del diseño de las herramientas de control, y es con base a este nefasto episodio en la contratación estatal colombiana que se diseñó la que tal vez sea una de las normas más contundentes en materia de la lucha anticorrupción, la Ley 1.474 de 2011.

Los esfuerzos del Estado debían estar destinados entonces a:

La aplicación de las leyes y las sanciones administrativas se centran en localizar la corrupción después que ésta ha ocurrido, si son eficaces, los riesgos percibidos de caer en la corrupción disuadirán a los servidores públicos de aceptar o extorsionar pagos, la meta es utilizar una combinación de premios (remuneración y prestaciones deseables) y castigos (sanciones legales y administrativas) para desalentar los sobornos (López Daza, 2012: 31).

Todo lo anterior, sin embargo, parece haberse quedado meramente en el papel de la norma, pues así lo demuestran los estudios sobre la percepción de la corrupción.

La ONG Transparencia por Colombia, en su informe anual del 2013, expuso que a pesar de que el Estado colombiano se ha dotado de fuertes herramientas para combatir la corrupción, la percepción de la sociedad frente el control que ejerce el Estado es completamente diferente y así lo expone textualmente en el mencionado informe:

Aunque el Estado colombiano ya cuenta con buenas herramientas para luchar contra la corrupción, como el Estatuto Anticorrupción, no se percibe que estas medidas 
sean efectivas. Estos avances normativos contrastan con los numerosos escándalos de corrupción que muchas veces terminan impunes. 'Mientras continuemos viendo que hay justicia dilatoria para los corruptos y que los niveles de sanción no son coherentes con el gran daño social y económico, la percepción de corrupción no va a disminuir', aseguró Elisabeth Ungar, directora ejecutiva de Transparencia por Colombia, Capítulo de TI. Ungar recordó además que Colombia aún tiene la deuda de una política integral de lucha contra la corrupción que «aterrice» el Estatuto Anticorrupción y que incluya medidas para dos de los eslabones más débiles en la persecución del delito: la investigación y la sanción Transparencia por Colombia, 2013).

Toda la anterior expresa una respuesta del Estado en lo que se refiere a buscar una solución al problema de la corrupción, tratando de recomponer el orden y el faro principal de la contratación estatal, siendo éste la satisfacción del interés general; pero queda la duda sobre si las normas han cumplido su meta, su finalidad o simplemente se han quedado como una compilación de buenos propósitos y permiten afirmar que entre más normatividad más corrupción existirá.

Se puede evidenciar que, a pesar de la existencia de una cantidad considerable de normatividad diseñada y tendiente a combatir los episodios de corrupción en la contratación estatal, ésta no ha disminuido, dando como primera impresión que la normatividad, más allá de un verdadera respuesta al fenómeno corruptivo, es una causal del sentimiento de inseguridad jurídica, de persecución, fiscalización por parte de los agentes de control sobre los funcionarios públicos e incluso los proponentes. Todo lo anterior llevando a desvirtuar el principio de ultima ratio por el que se debe seguir el ius puniendi del Estado.

Ha de quedar la reflexión sobre si el sistema de la contratación estatal es en la esencia de todas las normas que le conforman, modifican, adicionan, complementan un arreglo destinado al control de las acciones de corrupción o si por el contrario tienen un enfoque desviado para el que originalmente fueron diseñadas; pues entre tanta normatividad con similitud y coherencia, no hay claridad de cuál ha de ser aplicada, así como también se generan vacíos dentro del cuerpo normativo, lo que pareciere haber potencializado y aumentado los números de actuaciones corruptivas en Colombia, dando como resultado la apreciación que las normas no son efectivas y mucho menos cumplen con la finalidad para la que han sido estructurada y diseñadas.

De acuerdo con lo expuesto, se pueden confirmar dos premisas. Primero, que las normas son una respuesta en un intento del Estado de frenar o al menos reducir la problemática de la corrupción en la contratación estatal y, segundo, que las regulaciones normativas versus el número de casos corruptivos ocurridos parecieren evidenciar que las normas no han cumplido con su finalidad y que incluso generan temor y vacíos que son aprovechados por los agentes de la corrupción para continuar con su actividad.

La corrupción no es la consecuencia de una injerencia muy marcada del Estado, aun cuando una reglamentación demasiado rígida y poco flexible puede llegar a estimularla. 'El mercado contra el Estado', sin duda ésta no es la mejor fórmula para reducir la 
corrupción. No se logrará disminuir sensiblemente la corrupción si sólo se tiene una confianza ciega en las leyes del mercado, como piensa la mayoría de la corriente liberal. En lugar de oponer el Estado al mercado y servirse de esta oposición para explicar al mismo tiempo la corrupción, legitimarla y fundar las condiciones de su desaparición, sería más apropiado considerar que el mercado y el Estado no son dos conceptos desprovistos de historia (Salma Pierre, 1995: 66).

Es claro en la cita que la solución no es la estandarización de normas y procesos anticorruptivos, que muchas veces generan vacíos de interpretación e inseguridad jurídica, sino una política pública destinada a la atención y tratamiento de la problemática tomando como referente los propios procedimientos del Estado como solución.

\section{Efectos y consecuencias de la corrupción en la sociedad}

Cuando se habla de efectos y consecuencias de la corrupción, lo primero que se evidencia es un incumplimiento del deber ser de las cosas, de una desviación de lo que se debería hacer en el marco de los procesos de la contratación estatal materializado en el no cumplimiento del fin del Estado de la búsqueda y protección del interés general.

Tal vez la más trascedente de las consecuencias de la corrupción en el proceso de la contratación estatal queda en evidencia en los temas económicos que son adyacentes al proceso contractual de la Administración. Esto, en virtud del detrimento patrimonial al que se ve sometido el dinero público, pues en los eventos de corrupción el dinero del Estado asignado y destinando para la ejecución del objeto contractual se ve desviado para la satisfacción de los intereses personales de los agentes del proceso de contratación, pues:

La corrupción involucra a la estructura de la sociedad y de un gobierno, creando un escenario que imposibilita el desarrollo económico y social de las naciones. Una organización que mide el nivel de corrupción que mencioné en el capítulo 8 (Transparencia International) define la corrupción como «el abuso del poder encomendado para beneficio personal» (Bour, 2014: 2).

Es a partir de los daños económicos sufridos debido a la corrupción que se derivan una serie de situaciones negativas. Entre éstas el no cumplimiento del interés general, la generación de pobreza, atraso en infraestructura, entre otros.

Ciertamente las acciones sociales etiquetables como corruptas en la contratación estatal afectan el patrimonio del Estado, por cuanto no se cumple con la destinación de los recursos. En cifras se puede decir que «desde 1991 hasta el 2010, alrededor de \$ 189 billones, lo que equivale al 4\% del PIB del país durante esos 19 años», ${ }^{9}$ cifras para nada alentadoras, pues con este dinero se hubiesen solucionado grandes problemáticas sociales del país.

9. «El costo de la corrupción en Colombia», Revista Dinero, 12 de octubre de 2013, disponible en http:// bit.ly/2u5dYDT. 
Con casi cuatro años de vigencia de la Ley 1474, el panorama no parece haber tenido un cambio significativo, pues en el año 2013 «la corrupción le ha costado a la economía colombiana cerca de US $\$ 800$ millones, según un estudio de la Comisión Nacional Ciudadana para la Lucha Contra la Corrupción», ${ }^{10}$ lo que representa un serio problema para la economía del Estado y evidencia la inoperancia de los instrumentos normativos diseñados para limitar la ocurrencia de las acciones corruptibles o al menos sus efectos.

Un escenario menos alentador es el tema de infraestructura, pues con la corrupción muchos contratos estatales quedan en la mitad de su ejecución, atrasando así los avances necesarios para el país, lo cual le permitiría ser competitivos de cara a los nuevos paradigmas comerciales que los Tratados de Libre Comercio han configurado para el Estado colombiano:

El Índice de Competitividad Global del Foro Económico Mundial 2010-2011, muestra a Colombia en el puesto 68 (entre 139 países), pero si se mira desde el punto de vista de infraestructura en carreteras, el país cae al puesto 108, por debajo de Ecuador y Perú, que ocupan respectivamente los puestos 83 y 92. La reflexión final del estudio aclara que si bien Colombia muestra fortalezas competitivas en la calidad de su entorno macroeconómico, el tamaño de su mercado interno y el sofisticado nivel de sus empresas requieren más inversión para mejorar las redes de infraestructura y llevarlas a estándares de primera clase (Polanía, 2013).

Este atraso se enmarca en muchos factores tales como los ambientales, el orden público, la falta de presupuesto, pero el más preponderante de ellos sin lugar a duda es la acción social etiquetable de corrupta. Así entonces:

La corrupción y la ineficiencia de contratistas y servidores públicos parecen estar de moda, el renombrado caso de los Nule dispara las denuncias por obras sin terminar, aumentos injustificados en los gastos y fraudulentos procesos de contratación. Hasta el día de nuestro cierre editorial, Invias había presentado reportes de alrededor de 115 atrasos en 361 frentes de obra, motivos más que suficientes para que la paciencia del pueblo empiece a escasear (Polanía, 2013).

En materia de consecuencias de la corrupción, no se puede dejar de lado la situación más afectada con ocasión de su ocurrencia, siendo ésta la insatisfacción del interés general; pues como ya se ha dicho a lo largo del presente trabajo, es con base en el mencionado interés que se debe desarrollar todo el proceso de contratación del Estado, ya que el respeto y el cumplimiento a los procedimientos y principios en debida forma se estará prestando servicios públicos con calidad, continuidad y eficacia.

la eficiencia, la continuidad y la universalidad de la cobertura de los servicios públicos son fines legítimos y, además, constitucionalmente importantes para el logro del bienestar y el mejoramiento de la calidad de vida de la población y para la realización de los fines del Estado social de derecho. En efecto, tal como lo establece el artículo

10. «El costo de la corrupción en Colombia», Revista Dinero, 12 de octubre de 2013. 
365 Superior, el Estado debe asegurar que la prestación de los servicios públicos sea eficiente en todo el territorio nacional [...] (Sentencia de la Corte Constitucional Colombiana rol C-739-08, 2008).

Lamentablemente, la realidad del país es otra y la esencia de lo público ha sido desdibujada del mundo del ser, pues en muchas poblaciones es necesario el ofrecimiento de prebendas para la prestación de los servicios públicos. En los casos más graves, el dinero para su creación y funcionamiento ha sido apropiado indebidamente en más de una ocasión ${ }^{11}$ evitando la satisfacción de necesidades sociales tan importantes como la prestación del servicio de agua potable. Así pues:

El empobrecimiento y la exclusión social, junto con democracias débiles y permeadas por la corrupción, están entre los principales problemas que violan los derechos humanos en América Latina. Es un problema que no sólo involucra a los gobiernos de turno, sino también a toda la ciudadanía y al mismo modelo de Estado social de derecho que debe propender por la efectivización de los derechos de todo tipo. El Estado social y democrático de derecho es un Estado que debe intervenir en favor de los más débiles en pro de la igualdad y la justicia material, buscando satisfacer todo tipo de necesidades. En desarrollo del principio de solidaridad es necesario idearse mecanismos que le permitan cubrir el territorio y sus requerimientos (Arteaga, 2005: 94).

A priori se pensaría que los casos de corrupción no generan pobreza. Lo cierto es todo lo contrario: con el atraso en infraestructura y la insatisfacción del interés general por la prestación de servicios públicos con baja calidad, no continuidad, e ineficiencia o peor aún, la no prestación de los mismos, son generadores de la limitación y restricción a las posibilidades y oportunidades de desarrollo social. Todo lo anterior genera un sentimiento de desatención del Estado para con sus administrados que ven de manera impotente cómo el dinero de los impuestos con el que contribuyen es dilapidado en proyectos contractuales viciados de corrupción. Así pues «cuando la corrupción se difunde no sólo afecta el tejido social, sino que también influye en la crisis del Estado» (Salma Pierre, 1995: 66). Y precisamente se afecta el tejido social por medio de la pobreza que la acción social corruptiva genera.

La corrupción pareciera solamente tener consecuencias negativas con ocasión de su ocurrencia en la contratación estatal y esto es debido a que la misma es una acción social divergente en sentido negativo, pues sin posición en contrario la misma se aparta del deber ser de la contratación estatal, la cual debe ser el medio por excelencia para la búsqueda y satisfacción del interés general, en la correcta ejecución del presupuesto y patrimonio del Estado.

Igualmente, con la corrupción se está vulnerando el principio de la moralidad, que para el Consejo de Estado se define como:

11. Es importante recordar los casos de corrupción por concepto de construcción de acueductos de varios municipios de la costa atlántica de Colombia, o de Yopal, una de las capitales con mayores ingresos durante años por concepto de regalías de la explotación petrolífera en el país, que a la fecha no posee uno propio. 
el conjunto de principios, valores y virtudes fundamentales aceptados por la generalidad de los individuos, que deben informar permanentemente las actuaciones del Estado, a través de sus organismos y agentes, con el fin de lograr la convivencia de sus miembros, libre, digna y respetuosa, así como la realización de sus asociados tanto en el plano individual como en su ser o dimensión social. En el campo de la moralidad administrativa existen conductas no sólo generalmente aceptadas como inmorales, sino ilegales y hasta penalmente sancionadas, tales como el cohecho por dar u ofrecer, el tráfico de influencias y la celebración indebida de contratos (Sentencia del Consejo de Estado rol AP-054, 2001).

La moralidad entonces ha sido consagrada como principio rector de la función administrativa del Estado colombiano, así como derecho colectivo susceptible de ser protegido por la acción popular (contenida en la Constitución Política de Colombia de 1991), por lo cual los contratos que posiblemente estuvieren viciados de corrupción serán objeto de la mencionada acción dándose como eventual resultado la nulidad absoluta del mismo, truncando la satisfacción del interés general, ya no solamente como consecuencia de la corrupción, pues ahora será por mandato judicial en aras de detener la vulneración del derecho colectivo a la moralidad administrativa, que el juez ordenará la anulación del contrato dando por finalizado la producción de todos sus efectos jurídicos.

\section{Conclusión}

De todo lo expuesto, la primera y gran conclusión que se evidencia en términos sociológicos es que la corrupción no es en sí una acción social propiamente dicha, sino por el contrario ésta se construye en la categoría de etiqueta.

Es precisamente esta etiqueta la que por medio de las instituciones y agentes del proceso es asignada y define las diferentes acciones, como la construcción de pliegos sastres, sobornos, colusión de proponentes entre muchas otras actividades que generan una distorsión del proceso de contratación del Estado en virtud de la inobservancia de los principios establecidos por la Ley para esta actividad administrativa, que tiene por fin esencial la satisfacción del interés y bienestar general. En todo caso, no se puede perder de vista el alto impacto y mensaje social que trasmiten las acciones etiquetables de corruptas, esto en razón a la desatención que generan el desvío de los dineros públicos para la satisfacción de intereses personales.

Se tiene claro entonces el antagonismo entre la contratación estatal y la corrupción, la primera en razón a que busca satisfacer el interés general y las necesidades sociales de la colectividad, haciendo uso del presupuesto público para la prestación de servicios público con calidad, continuidad y eficacia. Mientras que la segunda busca todo lo contrario, es decir, satisfacer los intereses y necesidades propias de los agentes del proceso contractual (entiendo por estos agentes al servidor público y al proponente o contratista), siendo entonces divergente del deber ser social y normativo establecido para la contratación administrativa. 
Ahora bien, no debe perderse de vista la construcción significativa de instrumentos normativos para hacer frente a la corrupción. Es aquí en donde otro de los elementos de la sociología hace presencia, es decir el control penal. Dichos instrumentos son diseñados para sancionar y castigar a los funcionarios y demás agentes incursos en el proceso contractual cuando comente acciones etiquetables de corruptas. Lamentablemente, las estadísticas y precepción no sólo de la ciudadanía sino de las mismas entidades públicas denotan que dichos instrumentos generan más inseguridad jurídica que la que pretenden brindar.

El problema de las acciones corruptivas nace directamente de la esencia rígida e inflexible en la que las leyes y decretos constituyen el proceso de contratación pública en Colombia. Dicho proceso trata de blindarse cada vez más con normas que consagran ritualismos y garantías que buscan evitar la realización de actos de corrupción, sin embargo, lo que realmente se genera es un sentimiento de inseguridad jurídica que desemboca en el aumento de casos de corrupción evidenciando tal vez que el exceso de normatividad, situación que a todo lugar no es sana para el proceso contractual y los fines del Estado.

De otra parte, no se deben dejar de lado las consecuencias que la ocurrencia de la corrupción genera tanto para el Estado como para los administrados, en virtud de la insatisfacción del interés general. Pues ya no se estarán prestando servicios públicos con calidad, continuidad y eficiencia como criterios de prestación de los mismos. De otra parte, el atraso en la infraestructura del país genera nefastas consecuencias para la aplicación y competitividad de los paradigmas que proponen los TLC celebrados por Colombia con economías ciertamente más sólidas y competitivas a todo nivel.

Las acciones etiquetables de corruptas también son un foco para la descomposición del tejido social en virtud al considerable grado de pobreza que la misma corrupción genera, en razón a todos los factores y consecuencias presentados anteriormente.

Así pues, la corrupción es una etiqueta que ha de asignarse a todas aquellas acciones sociales que transgreden el deber ser de la contratación estatal. Situación evidenciable en el hecho de que ya no se está satisfaciendo con las compras públicas el interés general, sino que, por el contrario, se pretende buscar la satisfacción del interés particular de los distintos agentes del proceso contractual del Estado.

\section{Referencias}

Arteaga, Ana María (2005). «¿Es la corrupción la causa de la pobreza?» En Corrupción y derechos humanos: Estrategias comunes por la transparencia y contra la impunidad. Medellín: Editor IPC, Instituto Popular de Capacitación. Disponible en http://bit.ly/2v3TLlY.

Bejarano Ávila, Jesús Antonio (1996). «Estrategias contra la corrupción». En Andrés Dávila, Jorge Eastman y Fernando Rojas (1996), Descentralización y corrupción. Bogotá: Fescol. 
Bour, Enrique (2014). «Corrupción. Reflexiones en la Academia». Blog del autor. Disponible en http://bit.ly/2tHHBvq.

Conf LamneK, Siegfrid (1987). Teorías de la criminalidad. México: Siglo XXI.

Consejo de Estado, Sala de lo Contencioso Administrativo, Sección Cuarta. C.P. Expediente: AP-054 del 9 de febrero de 2001.

Corte Suprema de Justicia, Sala de Casación Penal, sentencia del 19 de agosto de 1976, disponible en Extractos de jurisprudencia de la sala penal de la Corte Suprema de Justicia, julio-diciembre de 1976, Colegio de Abogados Penalistas de Bogotá.

Corte Constitucional de Colombia, sentencia de Control de Constitucionalidad C-739-08, del 23 de julio de 2008.

García, Pablos (1999). Tratado de criminología. Valencia: Tirant lo Blanch.

IbARra PARdo, Gabriel (2011). «Guía para combatir la colusión en las licitaciones». Disponible en http://bit.ly/2vvlFJ5.

Lauzán, Silvana y Constanza Toro (2009). Anticorrupción: Actualizando los desafíos. Santiago: Universidad de Chile, Facultad de Derecho, Centro de Derechos Humanos. Disponible en http://www.libros.uchile.cl/387.

LEMERT, Edwin (1951). Social pathology. Nueva York: McGraw-Hil.

López DAZA, Germán Alonso (2012). La corrupción administrativa. Una aproximación a los factores y agentes generadores. Alemania: Academia Española.

Mauro, Paolo (1997). "Why worry about corruption». Economic Issues, 6 International Monetary Fund, Whasintgon D.C. Disponible en http://bit.ly/2h6VoeY.

MARTínez CÁrdenAs, Edgar Enrique y Juan Manuel Ramírez (2006). «La corrupción en la contratación estatal colombiana. Una aproximación desde el neoinstitucionalismo». Reflexión Política, 8 (15): 148-162. Disponible en http://www.redalyc.org/ pdf/110/11001512.pdf.

Pegorano, Juan S. (1998). «La corrupción como cuestión social y como cuestión penal». Delito y Sociedad. Revista de Ciencias Sociales, 8: 4-5. Disponible en http://bit. ly/2vegXyU.

Polanía, Daniel Fernando (2013). «Corrupción y malos manejos, radiografía de una nación carente de logística». Disponible en http://bit.ly/2wVd42v.

RuIz, Juan (2013). Efectos económicos de la corrupción en la contratación estatal en Colombia. Bogotá: Universidad Militar Nueva Granada. Repositorio de Tesis de Grado Especialización en Finanzas y Administración Pública.

SAlma Pierre, Valier Jacques (1995). «Corrupción y pobreza». Revista Espiral. Estudios sobre Estado y Sociedad, 1 (4): 45 a 67.

SANCHo, María Dolores (2014) «Sociología de la desviación: Howard Becker y la 'teoría interaccionista de la desviación'». Revista Conflicto Social, 7 (12): 65-87.

Silva García, Germán (2011). Criminología. Construcciones sociales e innovaciones teóricas. Bogotá: ILAE.

Silva García, Germán (2012). Criminología. Teoría sociológica del delito. Bogotá: ILAE. Ungar, Elisabet (s.f.). «La Corrupción: la enfermedad de Colombia». Disponible en 
http://www.humanumcolombia.org/corrupcion-la-enfermedad-de-colombia/

Transparencia por Colombia, Informe Anual 2013. Versión online disponible en http://bit.ly/2wloHOY.

Villamayor, Juan Carlos (2001). «Poder público, legitimidad y corrupción». Serie

Economía Colombiana y Coyuntura Política, núm. 282. Contraloría General de la República.

\section{Sobre los autores}

Carlos Fernando Amaya Rodríguez es abogado de Unicoc, especialista en Contratación Estatal de la Universidad de la Sabana, doctorando en Derecho de la Universidad de Buenos Aires. Profesor Investigador de la Institución Universitaria Colegios de Colombia Unicoc y en la Corporación Universitaria Republicana en las especializaciones en Derecho Público y Derecho Procesal Constitucional. Director Jurídico del Grupo Empresarial Biolegal. Su correo electrónico es cfamaya@unicoc.edu.co.

Laura Cristina Hernández es abogada de la Universidad Libre de Colombia. Especialista en Contratación Estatal de la Universidad de la Sabana y especialista en Derecho Administrativo de la Universidad del Rosario. Abogada del proyecto de interventoría de servicios de suministro de alimentación del Departamento de Nutrición Humana de la Facultad de Medicina de la Universidad Nacional de Colombia. Su correo electrónico es lauracristinahernandezg@gmail.com.

Zuleyma Méndez Prada es abogada de la Universidad Católica de Colombia. Especialista en Derecho Probatorio de la Universidad Católica de Colombia Especialista en Contratación Estatal de la Universidad de la Sabana. Actualmente se emplea como Directora Jurídica de la Concesión del SISGA. Su correo electrónico es zulymp@hotmail.com. 
